\title{
Early work load tests for evaluation of long-term prognosis of acute myocardial infarction
}

Sir,

We were interested by the work of Granath et al. (British Heart fournal, 1977, 39, 758-763), and as we have completed a similar study but with different results the comparison of both studies could be of interest.

We studied the prognostic significance of exercise-induced ventricular arrhythmias in 302 male patients, aged 51.9 years $(1 \mathrm{SD} \pm 7.3)$ and tested 67 days $( \pm 16)$ after an acute myocardial infarction. Their 'maximal' heart rate was $143 \mathrm{bpm}$ ( \pm 24), the 'maximal' systolic blood pressure $174 \mathrm{mmHg}( \pm 29)$, and the 'maximal' oxygen consumption $1463 \mathrm{ml} / \mathrm{min}$ ( \pm 488 ). The mean followup period was 1114 days $( \pm 547)$; total mortality was $28 / 302$ or $9 \cdot 2$ per cent.

Exercise-induced arrhythmias were noted by Granath et al. in 17 and 23 per cent respectively, 3 and 9 weeks after infarction, whereas we found a much higher prevalence of ventricular premature beats in 50 per cent, multiform ventricular premature beats in 20 per cent, repetitive ventricular premature beats in 14 per cent, and ventricular tachycardia in 2.6 per cent (Table); the prevalence

Table Prognostic significance of exercise-induced arrhythmias in 302 patients who underwent an exercise test within 3 months after an acute myocardial infarction

\begin{tabular}{lrlll}
\hline Arrhythmias & No. & \multicolumn{2}{l}{ Total mortality (\%) } & $P$ \\
\cline { 3 - 5 } & & $\begin{array}{l}\text { With } \\
\text { arrhythmias }\end{array}$ & $\begin{array}{l}\text { Without } \\
\text { arrhythmias }\end{array}$ \\
\hline Any VPB & 152 & 10.5 & 8.0 & NS \\
VPB $\geqslant 3 /$ min & 92 & 10.9 & 8.6 & NS \\
Multiform VPB & 59 & 8.5 & 9.5 & NS \\
Repetitive VPB & 44 & 4.6 & 10.1 & $<0.05$ \\
Ventricular tachycardia & 8 & 0 & 9.5 & NS \\
\hline
\end{tabular}

VPB, ventricular premature beat.

rates observed in our study are comparable with 39 per cent reported in coronary patients by Kosowsky et al. (1971), 50 per cent by Vuori et al. (1977) in post-infarction patients, and 41.7 per cent by Jelinek and Lown (1974) in 150 coronary patients who were not restricted by angina.

The 'low' prevalence rates reported by Granath et al. could be related to the low exercise performance of the subjects; their 'maximal' heart rates were only 117 and 126 at respectively 3 and 9 weeks compared with 143 in our patients.

The presence of either of these ventricular arrhythmias in our study was not associated with an increased subsequent mortality (Table). On the contrary, in patients with repetitive ventricular premature beats, mortality was even lower. Similar observations were made as to the incidence of new fatal or non-fatal cardiovascular events.

Our findings are comparable with those described by Kentala et al. (1975) and by Vuori et al. (1977); they suggest that exercise-induced ventricular arrhythmias in patients after an acute myocardial infarction could bear a different prognosis and could, therefore, have a different aetiology compared with ventricular arrhythmias detected at rest and during daily activities, clearly associated with an impaired prognosis.

The contrasting results with studies presented by Granath et al. (1977) could reflect a different significance of ventricular arrhythmias induced by low levels of exercise and present in only a smaller group of patients compared with the more prevalent ventricular arrhythmias described by various authors in less restricted patients.

G. De Backer, J. P. Van Durme, Department of Cardiology, Akademisch Ziekenhuis, Ghent, Belgium.

\section{References}

Jelinek, M. V., and Lown, B. (1974). Exercise stress testing for exposure of cardiac arrhythmias. Progress in Cardiovascular Diseases, 16, 497-522.

Kentala, E., Pyörälä, K., Heikkilä, J., Sarna, S., and Luurila, U. (1975). Factors related to long-term prognosis following acute myocardial infarction. Scandinavian fournal of Rehabilitation Medicine, 7, 118-124.

Kosowsky, B. D., Lown, B., Whiting, R., and Guiney, T. (1971). The occurrence of ventricular arrhythmias with exercise as compared to monitoring. Circulation, 44, 826-832.

Vuori, I., Hämäkäinen, H., and Kallio, V. (1977). Ventricular arrhythmias in exercise tests during the first year after acute myocardial infarction (abstract). Cardiology, 62, 87. 
This letter was shown to Dr Granath who replies as follows:

Sir, As to the lower prevalence of ventricular arrhythmias in our material we lack information of possible differences in type of exercise or definition of ventricular arrhythmias. On the assumption that such differences can be excluded, the lower relative load in our study seems to be a reasonable explanation. The differences in prognostic importance of ventricular arrhythmias during exercise is perhaps not surprising since ventricular arrhythmias at low loads could very well be expected to be more dangerous than those appearing at higher loads only. Such an interpretation obviously makes it difficult to determine optimal test loads in these patients. The differences in choice of load between the two studies were probably influenced by differences in principles of selection as indicated by a considerably higher mean age and mortality rate in our study during corresponding follow-up periods.

Arne Granath, Department of Clinical Physiology, Danderyd's Hospital, 18203 Danderyd, Sweden. 